\title{
Gestión de subproductos e impacto ambiental de la chatarrización vehicular del sector transporte público en Bogotá
}

Management of sub-products and environmental impact of the vehicle scrapping process in the public transport sector in Bogotá

\section{Gestion des sous-produits et impact environnemental du recyclage des véhicules de transport public de la ville de Bogotá}

Gestão de Subprodutos e Impacto Ambiental do tratamento da sucata veicular do setor de transporte público em Bogotá

Martha Emperatriz Pardo Parra * Alberto Uribe Jongbloed **

Fecha de recepción: 6 de octubre.

Fecha de aprobación: 28 de octubre.

Pp. 117-160.

* Magíster(c) en Ingeniería Civil, Escuela Colombiana de Ingeniería Julio Garavito. Docente de Cátedra, Universidad de La Salle.

** Ph.D. y Master of Science en Ingeniería Ambiental, Universidad de Cincinnati (Estados Unidos de América). Investigador y consultor en el área de agua potable y saneamiento básico, con énfasis en ingeniería de remediación. Docente titular de la Facultad de Ingeniería, Universidad EAN. 


\section{RESUMEN}

El proceso de chatarrización a nivel internacional, tiene incluido como alternativas de manejo la reutilización, tratamiento y aprovechamiento de los residuos con potencial de retorno al ciclo económico, lo que a su vez conlleva a la disminución de pasivos ambientales generados por la disposición de grandes volúmenes que disminuyen la vida útil de los rellenos sanitarios.Colombia cuenta con el aprovechamiento de los materiales ferrosos, pero se dejan de percibir ingresos por los no ferrosos, debido a que no se cuenta con la infraestructura para realizar el aprovechamiento y no se ha incurrido en estudios que vislumbren alternativas que disminuyan los residuos Ilevados a disposición final. El presente estudio realiza el análisis del proceso de chatarrización para el sector público, en este caso taxis, realizado por la empresa Sidenal, autorizada por la legislación colombiana para tal fin. Para el análisis de la composición de los residuos generados en el proceso se utilizó el vehículo SPARK que tiene mayor participación en la chatarrización, teniendo en cuenta las cifras aportadas por la empresa Sidenal.

\section{Palabras clave}

Desintegración vehicular, glasphalt, pirolisis, gasificación, coprocesamiento.

\section{ABSTRACT}

The international vehicle scrapping process has included the reuse, treatment and recovery of waste with potential return to the economic cycle as management alternatives, which in turn leads to reduced environmental liabilities generated by the disposal of large volumes that decrease the lifespan of landfills.

This study provides an analysis of the vehicle scrapping process for the public sector, in this case taxis, carried out by the company Sidenal which is authorized by colombian law for that purpose. For the analysis of the composition of the waste generated in the process, a Spark model vehicle was used, given that this model has the greatest share in the vehicle scrapping process; according to figures provided by the company Sidenal. 


\section{KEYWORDS}

Vehicle scrapping, glasphalt, pyrolysis, gasification, co-processing.

\section{RÉSUMÉ}

Au niveau international les processus de recyclage de véhicules fournissent des alternatives de réutilisation des matériaux et de traitement des résidus offrant un potentiel de réintégration dans le cycle économique. Ce processus de réutilisation des matériaux permet de réduire l'empreinte environnementale en générant de grandes quantités d'éléments disponibles offrant à leur tour une réduction de la durée de vie des décharges publiques. Cette étude analyse le processus de recyclage des véhicules de transport public réalisé par la société de taxis Sidenal en accord avec la législation colombienne. Cette analyse porte sur la composition des déchets générés par le processus de retraitement du véhicule Chevrolet SPARK étudié ici du fait d'une large participation de ce modèle au processus de recyclage, selon les données de Sidenal.

\section{MOTS CLEFS}

Désintégration de véhicules, Glasphalt, Pyrolyse, Gazéification,

\section{Resumo}

O processo de tratamento da sucata a nível internacional tem incluído como alternativas para o tratamento de sucatas a reutilização, o tratamento e aproveitamento dos resíduos com potencial de serem reutilizados e retornarem ao ciclo econômico, o que por sua vez leva à redução de passivos ambientais gerados pela eliminação de grandes volumes que diminuem o tempo de vida útil dos aterros sanitários. Este estudo fornece uma análise do processo de tratamento da sucata para o setor público neste caso, táxis, feita pela empresa Sidenal autorizada pela lei colombiana para o efeito. Para a análise da composição dos resíduos gerados no processo se utilizou o veículo SPARK que tem uma maior participação na demolição, dado os números fornecidos pela empresa Sidenal.

\section{PalaVRas-chave}

Desintegração veicular, glasphalt, pirólise, gaseificação, co-processamento. 


\section{Introducción}

ctualmente en Colombia la industria automotriz
constituye un elemento fundamental para el desarrollo
económico y la integración social, en particular, en lo que atañe al servicio público de transporte. Es tal el auge de este último sector que se ha incrementado la demanda de movilidad. Así mismo, la relevancia de la industria en mención es mayor a raíz de la baja calidad de los servicios de transporte, pues no responden a las necesidades de la población, que va en constante aumento. Según cifras de la Secretaría Distrital de Movilidad, para 2012, el parque automotor en Bogotá continuó con tendencia al alza y registró una tasa de crecimiento del $10,5 \%$ a nivel general. En lo que a los vehículos de servicio público se refiere, se tiene que en el año 2.012 había aproximadamente 67.150 vehículos en circulación en la capital, lo cual incide directamente en la movilidad de la ciudad.

La movilidad no es la única preocupación de las entidades distritales en relación con la industria automotriz $y$, en específico, relativa al sector del transporte público: otro problema es el alto costo en términos de afectación al medio ambiente, producido por la utilización de los vehículos, los cuales ocupan el segundo puesto entre las fuentes emisoras de dióxido de carbono. En adición a lo anterior, hay otra problemática que toma fuerza, a saber, la finalización de la vida útil de los vehículos, dado que hay escasos conocimientos en organización y gestión de los vehículos fuera de uso (VFU).

Existen grupos siderúrgicos como DIACO S. A. y Siderúrgica Nacional (Sidenal S. A.), los cuales son los únicos que cuentan con la autorización para efectuar el procedimiento de desintegración física de los vehículos de transporte público (sin contar el transporte especial) y privado en el Distrito Capital. Cabe anotar que Sidenal es la única encargada de los vehículos 
del sector de transporte público. Si bien en el momento solo se cuenta con las entidades mencionadas, quienes cumplan con los requisitos establecidos en la Resolución 381 del 10 de agosto de 2007 y reciban el aval de la Secretaría Distrital de Movilidad podrían adelantar el proceso citado.

La acción de Sidenal se enfoca en dos ejes: el primero es la reposición para acceder a la matrícula de un nuevo equipo, lo que garantiza que los vehículos que hayan cumplido su ciclo de vida útil sean sustituidos por equipos nuevos. El segundo eje de acción es la reducción de la sobreoferta con cargo a recursos del factor de calidad.

Con el aumento de la demanda de vehículos casi que proporcionalmente se origina un aumento de vehículos que salen de circulación. Para el manejo de estos últimos, el proceso de desintegración física y chatarrización es la opción más viable. Sin embargo, un vehículo está constituido de metales ferrosos y un conjunto de diferentes materiales cuya gestión no está definida, por lo cual los residuos resultantes intensifican la contaminación y carecen de potencial de aprovechamiento.

En función de lo anteriormente expuesto, el objetivo del presente proyecto de grado es generar alternativas de manejo de los materiales residuales del procedimiento de chatarrización que se lleva a cabo en Sidenal S. A., de modo tal que no sean un generador de pasivos ambientales, sino un subproducto con potencial de aprovechamiento. 


\section{Antecedentes}

uando se habla de Gestión de subproductos de vehículos al final de su vida útil, se deben tener en cuenta dos procesos para realizar el aprovechamiento de los mismos y que se desglosan a continuación:

- El proceso de chatarrización consiste en la destrucción de los elementos y componentes metálicos del automotor hasta convertir las partes metálicas ferrosa de desecho en chatarra y ser finalmente trasformadas para producir acero.

- Desintegración y/o Desmontaje Vehicular es la disgregación de los diferentes elementos y componentes del automotor, que mediante un esquema de gestión ambiental serán un subproducto de aprovechamiento.

Para abordar el tema en primera instancia se realiza una evaluación del comportamiento a nivel internacional, en cuanto al aprovechamiento de los subproductos generados de los procesos de chatarrización y desintegración de los vehículos fuera de uso, que para el caso del presente estudio se direcciona al sector público y específicamente en la ciudad de Bogotá.

A continuación se mencionan tres de las experiencias a nivel internacional, la primera de ellas en la Unión Europea, la segunda en México y por último en Japón, es importante resaltar que no son las únicas y que día a día se populariza esta actividad a nivel global.

El parlamento europeo y el consejo de la unión europea mediante la DIRECTIVA 2000/53/CE mencionan que a más 
tardar el 1 de enero de 2006, con respecto a todos los vehículos al final de su vida útil, se aumentará la reutilización y valorización hasta un mínimo del $85 \%$ del peso medio por vehículo y año. Dentro del mismo plazo se aumentará la reutilización y reciclado hasta un mínimo del $80 \%$ del peso medio por vehículo y año, asimismo menciona que a más tardar el 1 de enero de 2015, con respecto a todos los vehículos al final de su vida útil, se aumentará la reutilización y la valorización hasta un mínimo del $95 \%$ del peso medio por vehículo y año. En este mismo plazo, se aumentará la reutilización y reciclado hasta un mínimo del $85 \%$ del peso medio por vehículo y año (European Commission, 2000).

En la siguiente figura se presenta el diagrama del proceso de aprovechamiento de los subproductos en la Unión Europea, que como se mencionó, reglamenta esta actividad hasta en un $95 \%$. 
Figura 1. Sistema de manejo de vehículos fuera de uso dentro de la Unión Europea.

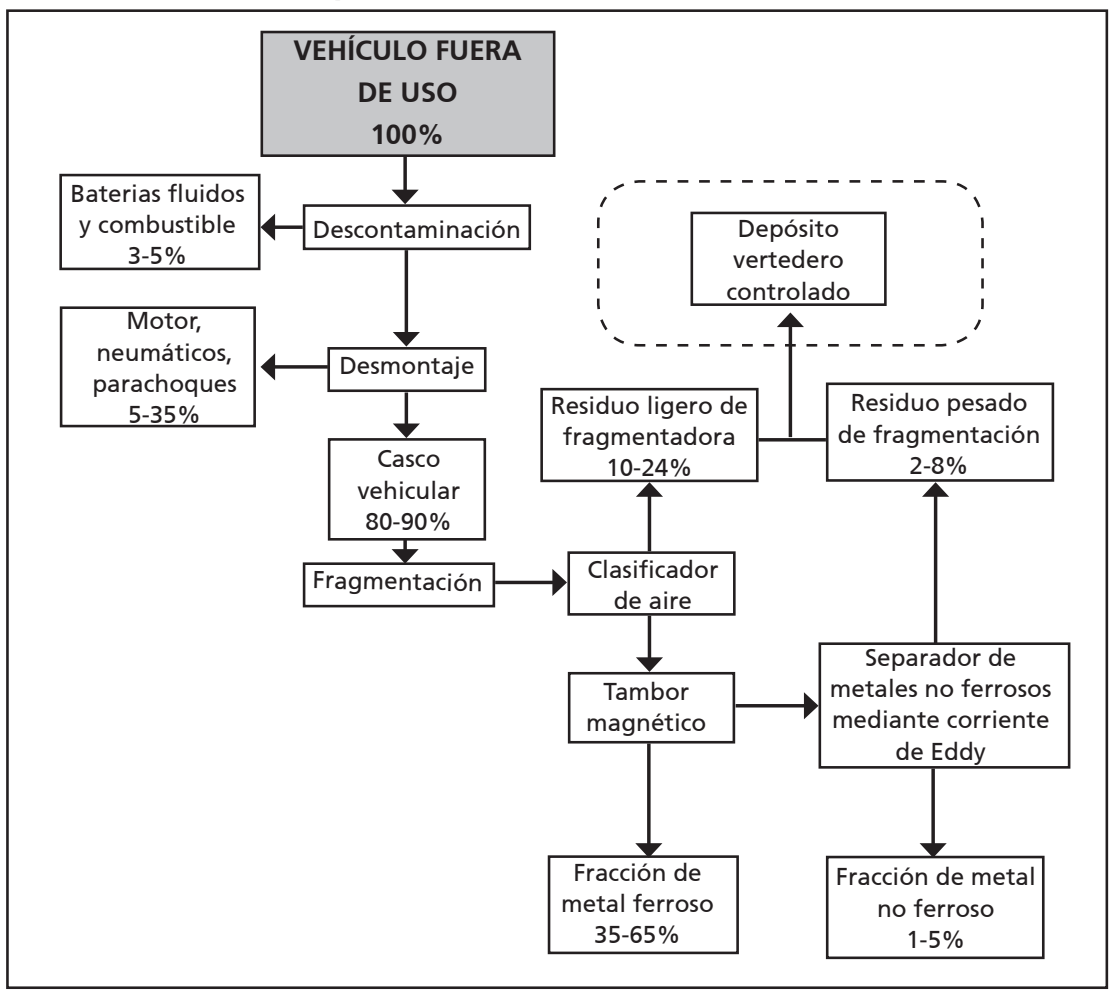

Fuente. Shin-Ichi, Hideto, Hiratsuka, Vandecasteele, et al, (2014).

México por su parte ha establecido los denominados planes de manejo de los vehículos fuera de uso donde contempla en su núcleo de operaciones cuatro tipos de instalaciones: los distribuidores y Centros Autorizados de Recepción (CAR), Los desmanteladores, los trituradores y los depósitos o corralones. De igual manera dentro de su modelo de gestión ambiental incluye la industria del Acero y fundición, que están asociados directamente al procesamiento de los productos obtenidos por los trituradores, principalmente en materiales ferrosos y no ferrosos provenientes del triturado de los VFU; la industria Cementera y los Relleno Sanitario están destinadas al 
manejo y disposición de los residuos de trituración de los vehículos; y las instalaciones para el tratamiento de los materiales o residuos peligrosos retirados de los VFU, estas instalaciones están destinadas a recibir y procesar para tratar, neutralizar o eliminar los residuos o materiales indicados como peligrosos.

En el caso de Japón la gestión es similar a la de la Unión Europea ya que las concepciones manejan procesos de descontaminación y desmontaje lo cual reduce considerablemente el peso del vehículo como se observa en la siguiente figura, sin embargo Japón maneja un modelo un poco más estricto basado en la responsabilidad social, encaminado a reducir los volúmenes llevados a disposición final.

Figura 2. Sistema de manejo de vehículos fuera de uso en Japón

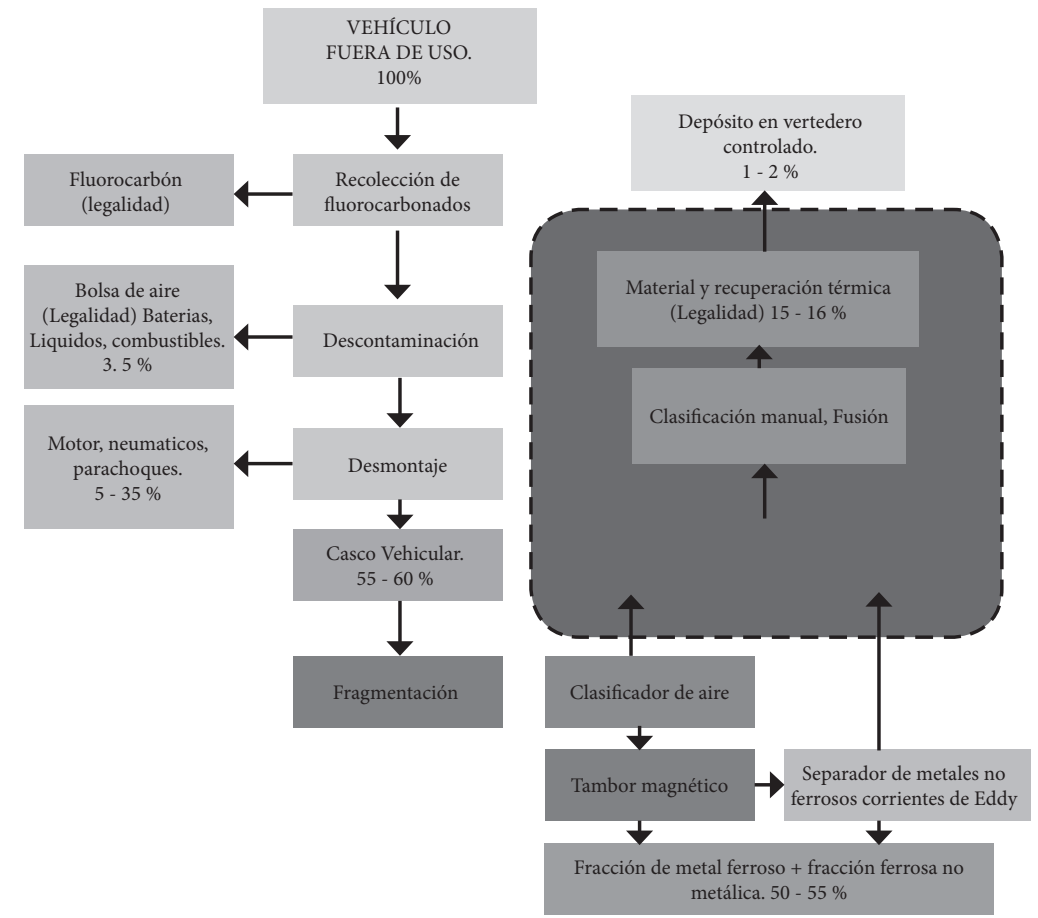

Fuente. Shin-Ichi, Hideto, Hiratsuka, Vandecasteele, et al, (2014). 
Colombia no es ajeno a la problemática ambiental y social que genera debido la mala gestión de los vehículos fuera de uso e igualmente de los procesos de chatarrización que se vienen implementando en el país.

Con la resolución 381 de 2.007 "Por la cual se establece el proceso de desintegración física total de vehículos de transporte de servicio público individual, colectivo y masivo en el Distrito Capital", se inicia el proceso de legalización, que continua con la expedición de la resolución 3253 de 2008 "Por medio de la cual se establece las condiciones y procedimientos para el Registro Inicial de Vehículos al Servicio Público y Particular de Transporte Terrestre Automotor de Carga por reposición y lo correspondiente a la desintegración física total de los vehículos de esta modalidad".

Es importante resaltar en primera instancia que en Colombia solo existen dos entidades autorizadas para llevar a cabo el proceso de chatarrización y estas son: Diaco S.A. y Sidenal S.A.

Otro aspecto a tener en cuenta y de gran importancia es que la única entidad desintegradora autorizada en Bogotá para la chatarrización de VFU (Vehículo fuera de uso) del sector servicio público es Sidenal S.A.

Además se debe resaltar que en Colombia el proceso de desintegración de vehículos esta direccionado por velar para que no se genere un mercado negro de repuestos, e incluso de vehículos que ya cumplieron su ciclo de vida útil, dado que la intención es retirar de las calles tecnología antigua, que es la que más contamina y reemplazarla por una más moderna y más limpia. 
En cuanto a la cantidad de vehículos con los que cuenta la ciudad de Bogotá, de acuerdo con las estadísticas de la Secretaría de Movilidad a diciembre del año 2.012 la ciudad contaba con aproximadamente 1.600 .000 vehículos particulares y 67.150 vehículos en circulación en la ciudad de Bogotá.

En 2012, la composición del parque automotor (Figura 3) sufrió una leve modificación con respecto a la registrada en 2011. En efecto, el servicio particular aumentó un punto porcentual su participación dentro del parque automotor alcanzando un $93 \%$ de representatividad, seguido por el servicio público con el $6 \%$ y el servicio oficial con el $1 \%$ (Secretaría de Movilidad, 2012).

Figura 3. Composición del parque automotor registrado 2012

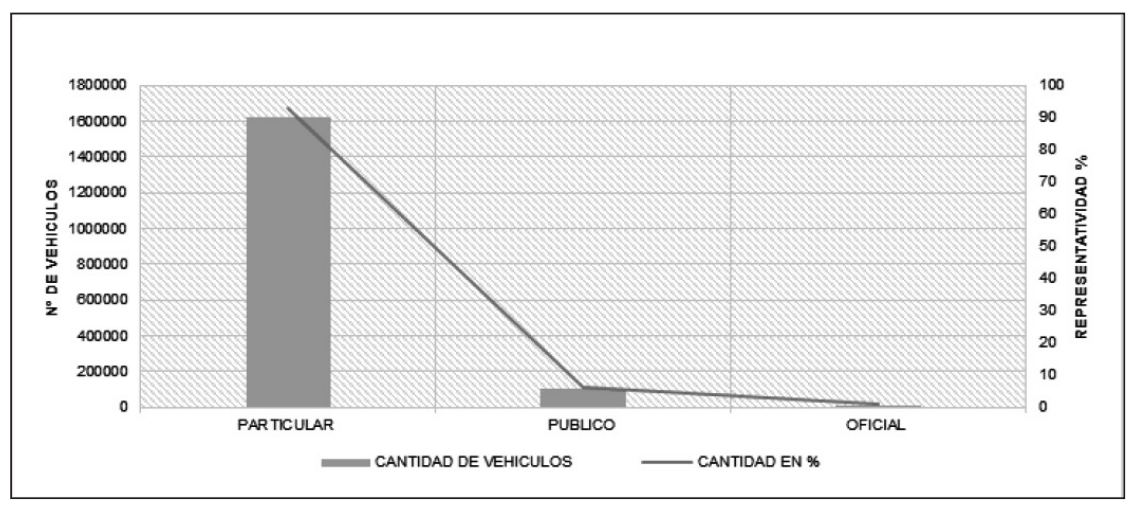

Fuente. Registro Distrital Automotor (RDA) - Concesión Servicios Integrales para la Movilidad (SIM). Cálculos Dirección de Estudios Sectoriales y de Servicios-SDM.

Pese a que la demanda de vehículos particulares en la ciudad de Bogotá es extensa, el análisis del presente trabajo se enfoca en los vehículos de servicio público, debido a que es el sector que ya presenta normativa. 
Las cifras de la secretaria de movilidad en el informe de 2012 muestran que la cantidad de vehículos de transporte público de pasajeros de radio de acción urbano, registrados en la ciudad al 31 de diciembre, son los que se presentan en la Tabla 1, se observa dichas cifras:

Tabla 1. Cantidad de vehículos públicos urbanos activos para el 2012 en la ciudad de Bogotá.

\begin{tabular}{|l|l|l|l|l|}
\hline \multicolumn{2}{|c|}{ Transporte Público Urbano } & Con T.O.a & Sin T.O.b & \multicolumn{1}{|c|}{ Total } \\
\hline \multirow{4}{*}{ Colectivo } & Bus & 5.574 & 403 & 5.977 \\
\cline { 2 - 5 } & Buseta & 2.626 & 426 & 3052 \\
\cline { 2 - 5 } & Microbus & 4.418 & 141 & 4.559 \\
\hline \multirow{4}{*}{ Individual } & Taxis & 49.555 & 2.059 & 51.614 \\
\hline \multirow{4}{*}{ Masivo } & Bus articulado & 1.341 & 13 & 1.354 \\
\cline { 2 - 5 } & Bus biarticulado & 92 & 0 & 92 \\
\cline { 2 - 5 } & Bus alimentador & 501 & 1 & 502 \\
\hline TOTAL & 64.107 & 3.043 & 67.150 \\
\hline
\end{tabular}

Fuente. Secretaría de Movilidad (2012).

- Los vehículos que se encuentran prestando el servicio en la ciudad, es decir, con Tarjeta de Operación vigente.

- Los vehículos que no tenían la Tarjeta de Operación vigente.

Para el desarrollo del presente trabajo se tuvieron en cuenta las cifras aportadas por la empresa Sidenal y muestran el número de vehículos de servicio público que ingresaron a la entidad en el periodo comprendido entre enero a noviembre del 2013, y que se encuentran discriminados de la Tabla 2: 
Tabla 2. Vehículos chatarrizados en las instalaciones de Sidenal - 2013.

\begin{tabular}{|l|c|c|c|c|c|}
\hline $\begin{array}{c}\text { Mes / año } \\
\mathbf{2 0 1 3}\end{array}$ & Buses & Busetas & Micro & Taxis & Total \\
\hline Enero & 14 & 33 & 5 & 243 & 295 \\
\hline Febrero & 38 & 53 & 9 & 323 & 423 \\
\hline Marzo & 32 & 46 & 9 & 258 & 345 \\
\hline Abril & 25 & 44 & 18 & 344 & 431 \\
\hline Mayo & 40 & 49 & 10 & 313 & 412 \\
\hline Junio & 52 & 35 & 18 & 254 & 359 \\
\hline Julio & 51 & 28 & 12 & 282 & 373 \\
\hline Agosto & 38 & 21 & 9 & 325 & 393 \\
\hline Septiembre & 36 & 15 & 13 & 381 & 445 \\
\hline Octubre & 42 & 22 & 8 & 355 & 427 \\
\hline Noviembre & 50 & 12 & 8 & 319 & 389 \\
\hline Total & 418 & 358 & 119 & 3.397 & 4.292 \\
\hline
\end{tabular}

Fuente. Sidenal S.A.

De acuerdo con la información aportada por Sidenal la cantidad de vehículos que ingresan al proceso de chatarrización va en incremento, este crecimiento está directamente relacionado con el aumento del parque automotor como se presentó anteriormente.

Sidenal dentro del proceso de chatarrización, realiza actividades como el desmonte de ciertos componentes de la batería y fluidos como aceites, combustibles, líquido de frenos, gas de aire acondicionado, líquido refrigerante, ácido de batería, entre otros, todo a través de entidades especializadas o gestores externos certificados que deben garantizar el manejo medioambiental, y estos a su vez debe cumplir con la normatividad vigente (Decreto 4741 de 2005), sin embargo el problema no solo radica en la gestión de los fluidos o los residuos peligrosos. 
De acuerdo con estudios realizados a nivel internacional más del $60 \%$ de un vehículo de servicio público está compuesto de metales ferrosos, y el $40 \%$ restante está hecho de otros materiales como: plástico, caucho, vidrio, metales no ferrosos, textiles y una mezcla de varios a la que se denomina tierra, entre otros. Actualmente Sidenal en su proceso productivo no posee una alternativa económica, técnica y ambientalmente viable para el manejo de estos subproductos.

Sidenal como entidad chatarrizadora en el municipio de Tocancipá, realiza la descontaminación y la reducción del volumen mediante compactación primaria y envía el material a la planta ubicada en el municipio de Sogamoso.

En esta última se realiza el proceso de fragmentación y por medio de un sistema de imanes se hace la separación del material ferroso, que es el insumo del proceso de siderurgia.

Es importante resaltar que la empresa realiza el aprovechamiento de los materiales ferrosos únicamente por lo se pierde el gran potencial de aprovechamiento que tienen los demás subproductos. El residuo de fragmentación ocupa una de las mayores problemáticas para la empresa, ya que para la fecha en la que se realizó el trabajo de campo para el presente trabajo existían 90.000 toneladas de residuos de fragmentación acumulados distribuidos en la tabla 3: 
Tabla 3. Cantidad de residuos de fragmentación acumulados en Sidenal S.A.

\begin{tabular}{|l|c|c|}
\hline \multicolumn{1}{|c|}{ Tipo de materiales } & $\begin{array}{c}\text { Cantidad } \\
\text { (Toneladas) }\end{array}$ & $\begin{array}{c}\text { Cantidad } \\
\text { (Porcentaje \%) }\end{array}$ \\
\hline $\begin{array}{l}\text { Metales recuperables (no } \\
\text { magnéticos) }\end{array}$ & 4500 & 5 \\
\hline Material inerte (tierra y vidrio) & 49500 & 55 \\
\hline $\begin{array}{l}\text { Material orgánico (caucho y } \\
\text { plástico) }\end{array}$ & 36000 & 40 \\
\hline Total & 90000 & 100 \\
\hline
\end{tabular}

Fuente. Elaboración propia de los autores.

Es importante mencionar que mensualmente se están generando 1400 toneladas aportantes al residuo de fragmentación acumulado.

\section{Resultados del proceso de investigación}

ara efectos de la formulación de alternativas de manejo para los subproductos mencionados anteriormente es importante tener en cuenta que en Colombia no se cuenta con información acerca de la composición física de los vehículos que son llevados al proceso de chatarrización, lo que conlleva a la falta de parámetros cuantitativos para formular estrategias de gestión para los subproductos generados.

De acuerdo con lo anterior y bajo la premisa de generar alternativas aplicables se realizó el desmonte de un vehículo tipo taxi, marca Chevrolet, modelo SPARK 2007. La selección de este vehículo se realizó teniendo en cuenta las 
tendencias en cuanto a reducción de tamaño del vehículo y composición de las partes.

En la siguiente figura se presenta el diagrama del proceso de trabajo de campo en el que se realizó el desmonte del vehículo mencionado.

Figura 4. Diagrama del proceso de determinación de la composición física del vehículo - caso de estudio

FASE I: Ingreso del vehículo al área de desmontaje

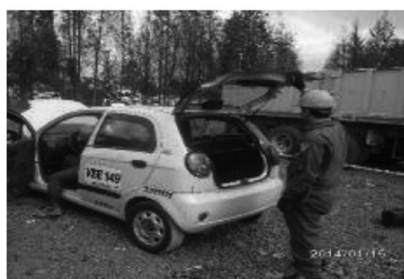

De acuerdo con el parque automotor que ingresa para el proceso de chatarrización en la empresa SIDENAL se selecciona el de mayor representación y corresponde a Chevrolet Spark modelo 2007

En esta fase se desmonta los componentes de mayor volumen y más fáciles de separar como los

parachoques, el tablero de instrumentos, las luminarias, etc.

FASE II: Desmontaje de componentes externos.

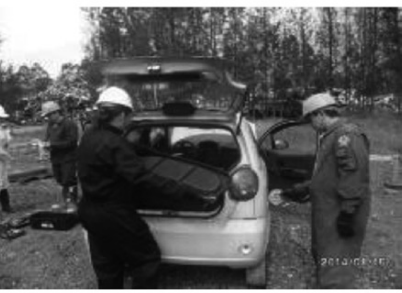

FASE III: Desmontaje de componentes interiores.

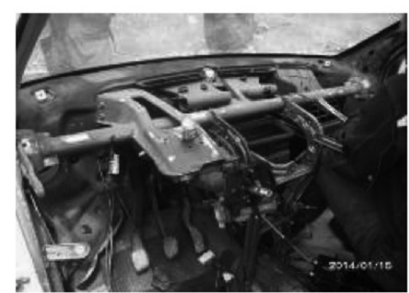

En esta fase se separan las partes interiores y los constituyentes de diferente material unidos entre sí, como el radiador, el múltiple de admisión, la bateria, pedales etc. 
Figura 4. Diagrama del proceso de determinación de la composición física del vehículo - caso de estudio (Continuación)
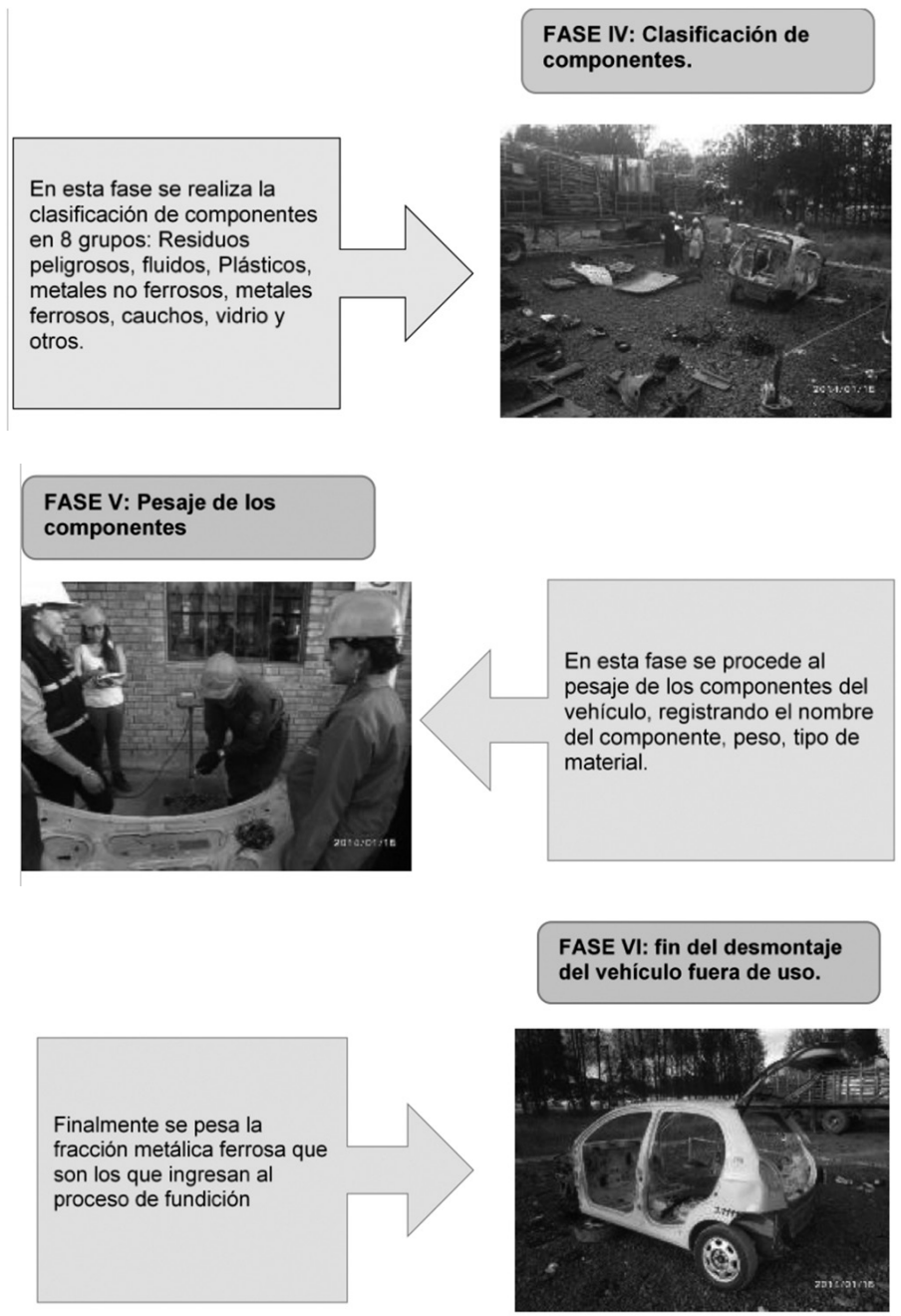

FASE VI: fin del desmontaje del vehículo fuera de uso.

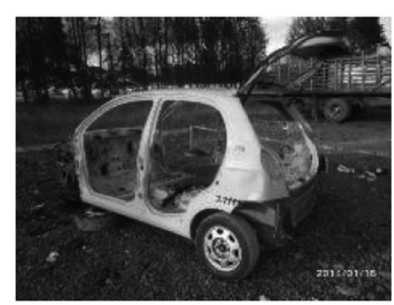

Fuente. Elaboración propia de los autores.

Con el desmontaje del vehículo se buscó tener la caracterización física detallada de los componentes tanto en peso como en porcentaje, y con esto poder determinar alternativas de manejo para cada uno de los componentes. 
Es importante resaltar que para el material ferroso se continúa con la alternativa utilizada actualmente, el uso como materia prima en el proceso de siderurgia.

En la siguiente tabla se presenta la composición física para el vehículo fuera de uso marca Chevrolet Spark modelo 2007 con un peso total de $870 \mathrm{~kg}$. El pesaje inicial del vehículo se realizó en báscula camionera y para los subproductos se utilizó báscula digital con capacidad de $300 \mathrm{~kg}$.

Tabla 4. Caracterización física del vehículo Chevrolet Spark modelo 2007.

\begin{tabular}{|l|c|c|c|c|}
\hline \multicolumn{1}{|c|}{ Componentes } & Material & Cantidad & Peso (kg) & $\%$ \\
\hline $\begin{array}{l}\text { Cubierta interior de } \\
\text { puertas }\end{array}$ & Plástico & 4 & 7,00 & $0,805 \%$ \\
\hline Cubiertas alm. Agua & Plástico & 2 & 2,00 & $0,230 \%$ \\
\hline $\begin{array}{l}\text { Panel de } \\
\text { instrumentos }\end{array}$ & Plástico & 1 & 4,20 & $0,483 \%$ \\
\hline $\begin{array}{l}\text { Parte interior panel } \\
\text { de instrumentos }\end{array}$ & Plástico & 1 & 1,50 & $0,172 \%$ \\
\hline $\begin{array}{l}\text { Soporte superior } \\
\text { baúl }\end{array}$ & Plástico & 1 & 1,80 & $0,207 \%$ \\
\hline $\begin{array}{l}\text { Consola caja } \\
\text { cambios }\end{array}$ & Plástico & 1 & 1,70 & $0,195 \%$ \\
\hline $\begin{array}{l}\text { Parachoques } \\
\text { delantero }\end{array}$ & Plástico & 1 & 3,20 & $0,368 \%$ \\
\hline Parachoques trasero & Plástico & 1 & 2,70 & $0,310 \%$ \\
\hline Estopas & Plástico & 2 & 1,50 & $0,172 \%$ \\
\hline Farolas & Plástico & 2 & 4,60 & $0,529 \%$ \\
\hline $\begin{array}{l}\text { Cubierta luminaria } \\
\text { traseras }\end{array}$ & Plástico & 2 & 0,20 & $0,023 \%$ \\
\hline $\begin{array}{l}\text { Cubiertas } \\
\text { amortiguador }\end{array}$ & Plástico & 2 & 1,30 & $0,149 \%$ \\
\hline
\end{tabular}


Tabla 4. Caracterización Física del vehículo Chevrolet Spark modelo 2007 (Continuación)

\begin{tabular}{|l|c|c|c|c|}
\hline \multicolumn{1}{|c|}{ Componentes } & Material & Cantidad & Peso $(\mathbf{k g})$ & $\%$ \\
\hline $\begin{array}{l}\text { Conducto sistema } \\
\text { Aire acondicionado }\end{array}$ & Plástico & 2 & 0,30 & $0,034 \%$ \\
\hline Conductos internos & Plástico & 2 & 2,40 & $0,276 \%$ \\
\hline $\begin{array}{l}\text { Tapa puerta trasera } \\
\text { baul }\end{array}$ & Plástico & 1 & 0,40 & $0,046 \%$ \\
\hline $\begin{array}{l}\text { Soporte interior } \\
\text { guantera }\end{array}$ & Plástico & 1 & 1,20 & $0,138 \%$ \\
\hline Cubierta retrovisor & Plástico & 2 & 0,40 & $0,046 \%$ \\
\hline $\begin{array}{l}\text { Carcasa multiple de } \\
\text { admisión }\end{array}$ & Plástico & 1 & 4,20 & $0,483 \%$ \\
\hline Filtro de aire I & Plástico & 1 & 1,40 & $0,161 \%$ \\
\hline Filtro de aire II & Plástico & 1 & 0,60 & $0,069 \%$ \\
\hline $\begin{array}{l}\text { Parachoques } \\
\text { puertas }\end{array}$ & Plástico & 4 & 1,20 & $0,138 \%$ \\
\hline Asiento trasero & Plástico & 1 & 7,00 & $0,805 \%$ \\
\hline Guardabarros & Plástico & 2 & 2,80 & $0,322 \%$ \\
\hline Carcasas calefacción & Plástico & 2 & 1,70 & $0,195 \%$ \\
\hline Ventilador radiador & Plástico & 1 & 0,70 & $0,080 \%$ \\
\hline $\begin{array}{l}\text { Paral cinturon de } \\
\text { seguridad }\end{array}$ & Plástico & 4 & 2,00 & $0,230 \%$ \\
\hline Consolas varias & Plástico & 4 & 3,00 & $0,345 \%$ \\
\hline Rejilla parabrisa & Plástico & 1 & 0,90 & $0,103 \%$ \\
\hline Guantera & Plástico & 1 & 0,90 & $0,103 \%$ \\
\hline Asiento delantero & Plástico & 2 & 3,60 & $0,414 \%$ \\
\hline Espumas varias & Plástico & 1 & 0,70 & $0,080 \%$ \\
\hline $\begin{array}{l}\text { Tablero de mando } \\
\text { del sistema de aire } \\
\text { acondicionado }\end{array}$ & Caucho & & 11,50 & $1,322 \%$ \\
\hline Otros I & & & & \\
\hline Cauchos varios & & & & \\
\hline
\end{tabular}


Tabla 4. Caracterización Física del vehículo Chevrolet Spark modelo 2007 (Continuación)

\begin{tabular}{|l|c|c|c|c|}
\hline \multicolumn{1}{|c|}{ Componentes } & Material & Cantidad & Peso (kg) & $\%$ \\
\hline Neumático & Caucho & 4 & 27,20 & $3,126 \%$ \\
\hline Triángulo & Vidrio & 2 & 0,80 & $0,092 \%$ \\
\hline Retrovisor & Vidrio & 2 & 0,20 & $0,023 \%$ \\
\hline Lateral puerta & Vidrio & 4 & 11,60 & $1,333 \%$ \\
\hline Panorámico & Vidrio & 1 & 11,50 & $1,322 \%$ \\
\hline Trasero & Vidrio & 1 & 8,50 & $0,977 \%$ \\
\hline Calefacción & No ferroso & 1 & 0,60 & $0,069 \%$ \\
\hline Catalizador & No ferroso & 1 & 3,20 & $0,368 \%$ \\
\hline $\begin{array}{l}\text { Caja de motor } \\
\text { (culata) }\end{array}$ & No ferroso & 1 & 17,60 & $2,023 \%$ \\
\hline Pistoles motor & No ferroso & 4 & 6,80 & $0,782 \%$ \\
\hline $\begin{array}{l}\text { Caja de velocidad } \\
\text { (carcazas) }\end{array}$ & No ferroso & 1 & 12,80 & $1,471 \%$ \\
\hline Arranque & No ferroso & 1 & 4,40 & $0,506 \%$ \\
\hline Cables generales & No ferroso & & 5,90 & $0,678 \%$ \\
\hline Motoventilador & No ferroso & 2 & 0,60 & $0,069 \%$ \\
\hline Calefacción motor & No ferroso & 1 & 0,18 & $0,021 \%$ \\
\hline Otros II & No ferroso & & 2,00 & $0,230 \%$ \\
\hline Batería & Respel & 1 & 14,20 & $1,632 \%$ \\
\hline Radiador & Respel & 1 & 2,20 & $0,253 \%$ \\
\hline $\begin{array}{l}\text { Múltiple de } \\
\text { admisión }\end{array}$ & Respel & 1 & 17,60 & $2,023 \%$ \\
\hline $\begin{array}{l}\text { Pastillas } \\
\text { impregnadas de } \\
\text { asbesto }\end{array}$ & Respel & & 0,59 & $0,068 \%$ \\
\hline $\begin{array}{l}\text { Bujías impregnado } \\
\text { de gasolina }\end{array}$ & $\begin{array}{l}\text { Recipiente líquido } \\
\text { de frenos }\end{array}$ & 1 & 0,12 & $0,014 \%$ \\
\hline & Respel \\
\hline
\end{tabular}


Tabla 4. Caracterización Física del vehículo Chevrolet Spark modelo 2007 (Continuación)

\begin{tabular}{|c|c|c|c|c|}
\hline Componentes & Material & Cantidad & Peso $(\mathrm{kg})$ & $\%$ \\
\hline Computador & Respel & 1 & 0,64 & $0,074 \%$ \\
\hline Bombillas & Respel & & 0,20 & $0,022 \%$ \\
\hline $\begin{array}{l}\text { Caja de cambios } \\
\text { impregnado de } \\
\text { valvulina }\end{array}$ & Respel & 1 & 26,10 & $3,000 \%$ \\
\hline Rin & $\begin{array}{l}\text { Metal } \\
\text { ferroso }\end{array}$ & 2 & 3,80 & $0,437 \%$ \\
\hline $\begin{array}{l}\text { Puerta delantera } \\
\text { con vidrio }\end{array}$ & $\begin{array}{l}\text { Metal } \\
\text { ferroso }\end{array}$ & 1 & 18,80 & $2,161 \%$ \\
\hline $\begin{array}{l}\text { Puerta trasera con } \\
\text { vidrio }\end{array}$ & $\begin{array}{l}\text { Metal } \\
\text { ferroso }\end{array}$ & 1 & 14,80 & $1,701 \%$ \\
\hline Capo & $\begin{array}{l}\text { Metal } \\
\text { ferroso }\end{array}$ & 1 & 7,20 & $0,828 \%$ \\
\hline Tornillos & $\begin{array}{l}\text { Metal } \\
\text { ferroso }\end{array}$ & & 2,90 & $0,333 \%$ \\
\hline Casco vehicular & $\begin{array}{l}\text { Metal } \\
\text { ferroso }\end{array}$ & 1 & 544,16 & $62,547 \%$ \\
\hline Techo & Variable & 1 & 2,30 & $0,264 \%$ \\
\hline Timón & $\begin{array}{l}\text { Aluminio, } \\
\text { espuma, } \\
\text { ferroso }\end{array}$ & 1 & 1,50 & $0,172 \%$ \\
\hline $\begin{array}{l}\text { Cinturón de } \\
\text { seguridad }\end{array}$ & $\begin{array}{c}\text { Textil, } \\
\text { Plástico, } \\
\text { metal } \\
\text { ferroso y } \\
\text { no ferroso }\end{array}$ & 2 & 2,80 & $0,322 \%$ \\
\hline Total peso kg & & & 870,00 & $100 \%$ \\
\hline
\end{tabular}

Fuente. Elaboración propia de los autores. 
Es importante tener en cuenta que en la clasificación se contemplaron los siguientes aspectos:

- El componente llamado OTROS I corresponden a pequeñas partes plásticas adheridas a otros componentes de mayor tamaño sean otros componentes plásticos de mayor volumen como a metales ferrosos y no ferrosos.

- CAUCHOS VARIOS hacen parte de un selecto grupo de empaques y recubrimientos, a su vez representan la pieza intermedia para evitar la fricción de componentes como por ejemplo el vidrio y el metal.

- OTROS II son un selecto grupo de pequeñas partes no ferrosos adherida a otros componentes de mayor tamaño sean otros metales no ferrosos o metales ferrosos o plástico; el radiador es considerado un Residuo peligroso (RESPEL) sin embargo, posee componentes importantes en metales no ferrosos. Para hacer una apreciación un poco más detallada en la identificación de los subproductos de un vehículo fuera de uso, ( Figura 5).

Figura 5. Composición física de los subproductos de residuos de los vehículos fuera de uso de servicio público.

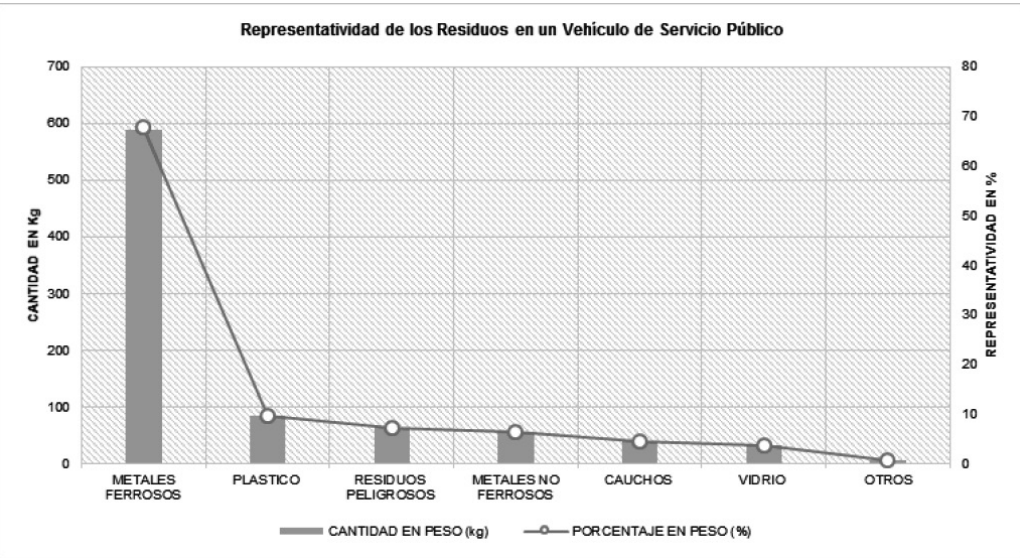

Fuente. Elaboración propia de los autores. 
De acuerdo con los resultados aportados por la tabla 4 en orden de importancia peso y representatividad se tiene que el $62.54 \%$ del vehículo está compuesto de metales, $9.67 \%$ corresponden a plásticos, en tercer lugar los residuos peligrosos con un $7.16 \%$, los metales no ferrosos corresponden al $6.22 \%$, para cauchos $4.45 \%$, vidrio 3,74\% y a otros con porcentaje de $0.76 \%$, estos últimos corresponden a un grupo de componentes constituidos de diferentes tipos de materiales (espuma, plástico, aluminio textil, cartón entre otros), se toma este componente teniendo en cuenta que la separación de los mismos requiere de un proceso complejo.

\section{Evaluación ambiental de la chatarrización}

- eniendo en cuenta que todos los impactos generados por el proceso de chatarrización tienen injerencia directa en el componente social se realiza la evaluación del impacto ambiental aplicando la matriz de Leopold en donde se contemplan los componentes y las actividades desarrolladas en las áreas de influencia.

En la siguiente tabla se presentan las áreas de influencia y descripción de las dos zonas en las que realiza las actividades la empresa Sidenal. 
Tabla 5. Áreas de influencia de las sedes Sidenal

\begin{tabular}{|c|l|}
\hline Sede & \multicolumn{1}{c|}{ Observación } \\
\hline Tocancipá & $\begin{array}{l}\text { Es importante mencionar que el predio de Sidenal } \\
\text { Tocancipá se ubica en un área de tipo industrial, } \\
\text { hay un asentamiento cercano llamado la Diana que } \\
\text { está localizado sobre la carretera central del norte } \\
\text { entre los sectores de Tibitó e Industrial en cercanía } \\
\text { del Parque Jaime Duque. Este asentamiento se } \\
\text { desarrolla a lo largo de la vía especialmente en el } \\
\text { costado oriental. La cercanía con Sidenal es entre } \\
\text { 400 a } 600 \text { metros. }\end{array}$ \\
\hline Sogamoso & $\begin{array}{l}\text { Se observa que las instalaciones de la empresa se } \\
\text { encuentran dentro del perímetro urbano con uso } \\
\text { del suelo industrial. Es importante resaltar que la } \\
\text { empresa cuenta con medidas de manejo ambiental } \\
\text { en las chimeneas, pero la población cercana puede } \\
\text { verse impactada negativamente por los impactos } \\
\text { generados: ruido y emisión de material particulado. }\end{array}$ \\
\hline
\end{tabular}

Fuente. Elaborado por los autores con base en Google earth.

En la figura 6, se presenta el registro fotográfico de diferentes áreas del proceso de chatarrización, que incluyen las realizadas en los municipios de Tocancipá y Sogamoso. 
Figura 6. Diferentes vistas de los residuos generados por el proceso de chatarrización en Sidenal S.A.

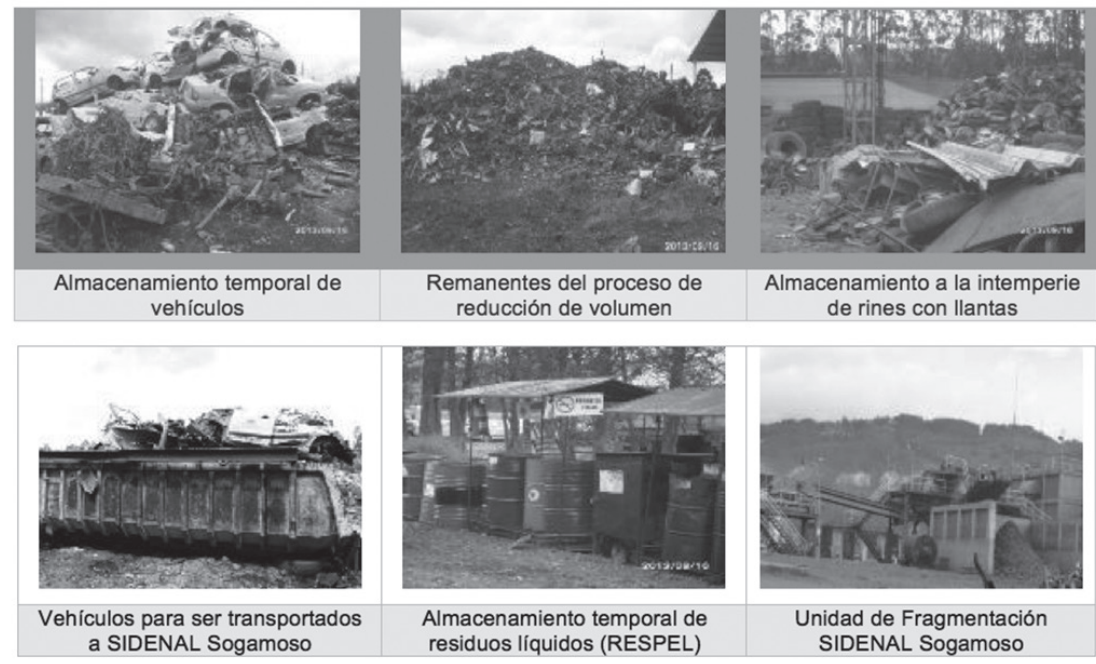

Fuente. Elaboración propia de los autores.

\subsection{Matriz de Leopold (ESPOL)}

Impacto ambiental es la alteración de orden negativo o positivo que se produce en el ambiente cuando se lleva a cabo un proyecto, obra o actividad, sumando sus efectos a corto, mediano y largo plazo de cualquier acción directa o indirectamente al ser humano y a los ambientes físicos, biológicos, sociales, económicos y culturales que lo conforman.

Para la evaluación del impacto ambiental se tuvieron en cuenta los siguientes impactos:

- Impactos por la intensidad o grado de destrucción

Alto. Aquel cuyo efecto se manifiesta como una modificación del medio ambiente, de los recursos naturales o de sus procesos fundamentales de funcionamiento, que produzca 
o pueda producir en el futuro repercusiones apreciables en los mismos.

Mínimo o bajo. Aquel cuyo efecto expresa una destrucción mínima del factor considerado.

Medio. Aquel cuyo efecto se manifiesta como una alteración del medio ambiente o de algunos de sus factores, cuyas repercusiones en los mismos se consideran situadas entre los niveles anteriores.

\section{- Impactos por su duración}

Temporal. Aquel cuyo efecto supone alteración no permanente en el tiempo, con un plazo temporal de manifestación.

Medio. Aquel cuyo efecto supone alteración en un corto mediano de tiempo.

Permanente. Aquel cuyo efecto supone una alteración indefinida en el impacto de los factores medioambientales predominantes en la estructura o en la función de los sistemas de relaciones ecológicas o ambientales en el lugar. Es decir aquel impacto que permanece en el tiempo. A efectos prácticos, se considera como permanente un impacto con una duración superior a 10 años. (Construcción de carreteras, conducción vista de agua de riego, etc.).

- Impactos por extensión o influencia

Puntual. Cuando la acción impactante produce un efecto muy localizado.

Parcial o local. Aquel cuyo efecto supone una incidencia apreciable en el medio. 
Extremo o regional. Aquel cuyo efecto se detecta en una gran parte del medio considerado.

Total o nacional o mundial. Aquel cuyo efecto se manifiesta de manera generalizada en todo el entorno considerado.

En la tabla 6 se presenta la forma de calificación de la matriz de Leopold.

Tabla 6. Forma de calificación de magnitud e importancia de la matriz de Leopold.

\begin{tabular}{|l|l|l|l|l|c|}
\hline \multicolumn{3}{|c|}{ MAGNITUD } & \multicolumn{3}{c|}{ IMPORTANCIA } \\
\hline Intensidad & Afectación & Calificación & Duración & Influencia & Calificación \\
\hline Baja & Baja & $-1 \circ+1$ & Temporal & Puntual & 1 \\
\hline Baja & Media & $-2 \circ+2$ & Media & Puntual & 2 \\
\hline Baja & Alta & $-3 \circ+3$ & Permanente & Puntual & 3 \\
\hline Media & Baja & $-4 \circ+4$ & Temporal & Local & 4 \\
\hline Media & Media & $-5 \circ+5$ & Media & Local & 5 \\
\hline Media & Alta & $-6 \circ+6$ & Permanente & Local & 6 \\
\hline Alta & Baja & $-7 \circ+7$ & Temporal & Regional & 7 \\
\hline Alta & Media & $-8 \circ+8$ & Media & Regional & 8 \\
\hline Alta & Alta & $-9 \circ+9$ & Permanente & Regional & 9 \\
\hline Muy Alta & Alta & $-10 \circ+10$ & Permanente & Nacional & 10 \\
\hline
\end{tabular}

Fuente. ESPOL Escuela Superior Politécnica del Litoral.

En la Tabla 7, se presentan los resultados obtenidos de la aplicación de la matriz de Leopold para los diferentes componentes analizados: Geosférico, Atmosférico, Hídrico, Ecosistémico y Social, teniendo en cuenta las actividades realizadas en las dos sedes de la empresa Sidenal. 


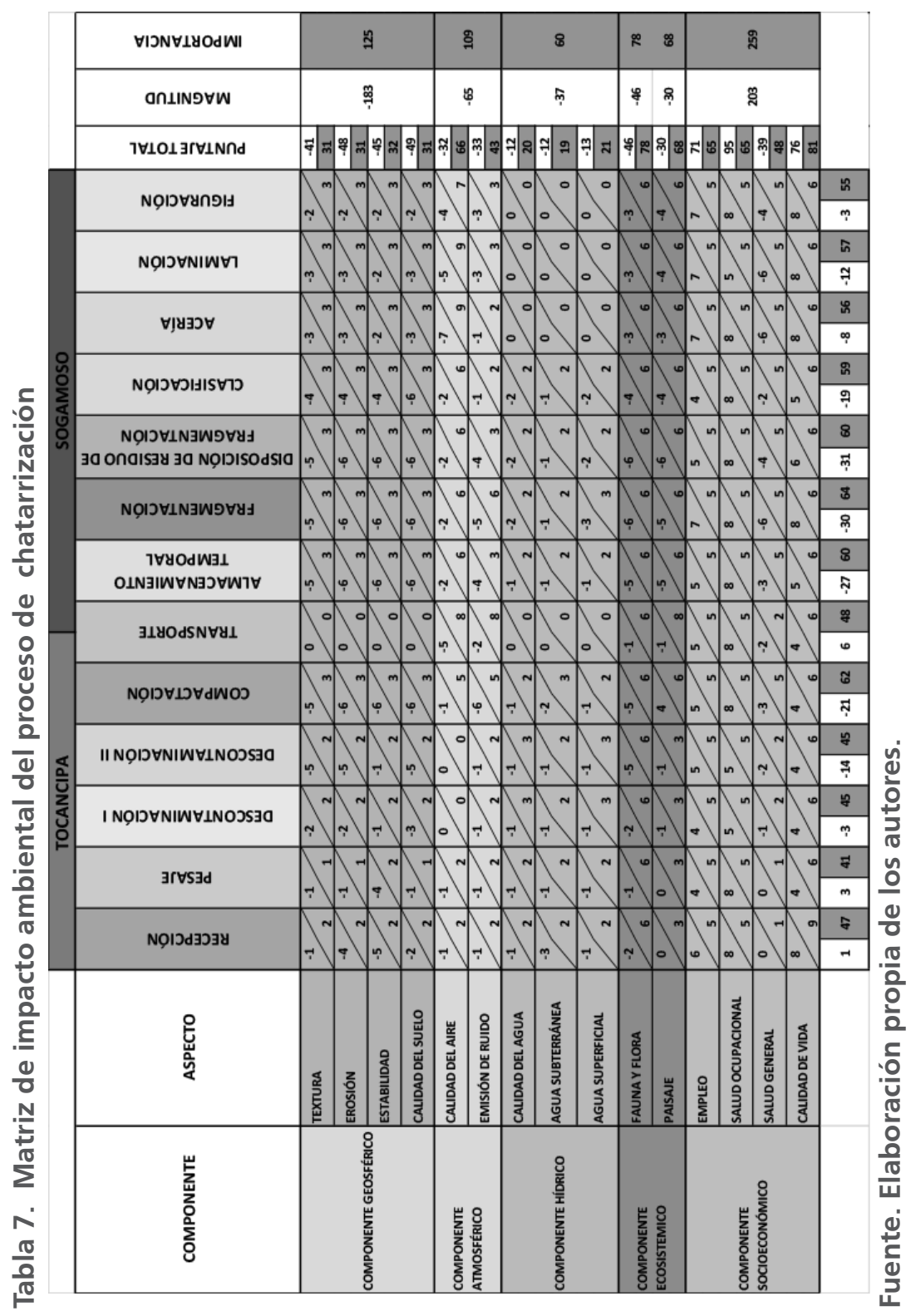


Los resultados obtenidos a raíz de la matriz de impactos se muestran en la siguiente tabla, escogiéndose cuatro intervalos de evaluación; leve, moderado, grave y crítico.

Tabla 8. Resultados matriz de impacto ambiental de la chatarrización vehicular.

\begin{tabular}{|c|c|c|c|}
\hline \multicolumn{4}{|c|}{ TIPO DE IMPACTO } \\
\hline LEVE & MODERADO & GRAVE & CRITICO \\
\hline-12 a -21.25 & -21.25 a -30.5 & -30.5 a $-39,75$ & -39.75 a -49 \\
\hline $\begin{array}{c}\text { Agua } \\
\text { superficial }\end{array}$ & Paisaje & Calidad de aire & $\begin{array}{c}\text { Calidad del } \\
\text { suelo }\end{array}$ \\
\hline $\begin{array}{c}\text { Agua } \\
\text { subterránea }\end{array}$ & & $\begin{array}{c}\text { Emisión de } \\
\text { ruido }\end{array}$ & Erosión \\
\hline $\begin{array}{c}\text { Calidad de } \\
\text { agua }\end{array}$ & Salud general & Flora y fauna \\
\hline & & & Estabilidad \\
\hline
\end{tabular}

Fuente. Elaboración propia de los autores.

De acuerdo con los resultados de la evaluación ambiental y que se presentan en la Tabla 8 se observa que los componentes más afectados son el geosférico y ecosistémico. En el componente geosférico el impacto crítico hace referencia al suelo en los aspectos de calidad, erosión, estabilidad y textura.

- La textura tiene que ver con la facilidad con que se puede trabajar el suelo, la cantidad de agua y aire que retiene y la velocidad con que el agua penetra en el suelo y lo atraviesa. La textura del suelo tiene una magnitud considerable principalmente en las 
etapas de descontaminación, acopio, fragmentación y compactación, porque son etapas que se realizan a la intemperie sobre el entorno natural del suelo, afectando las condiciones mencionadas.

- Erosión es la pérdida gradual de los materiales que forman el suelo originado por los procesos erosivos. La erosión tiene una magnitud alta en los componentes de descontaminación II, compactación, acopio y fragmentación, debido a actividades del proceso de cargue y descargue de material con maquinaria pesada, esto genera impacto en la capa orgánica del suelo, removiéndola y dejándolo expuesto a otros agentes que erosionan como el viento y la lluvia.

- Estabilidad, es la capacidad que poseen los agregados del suelo para soportar la tensión de diferentes fuerzas sin deformación de los mismos. La estabilidad tiene una magnitud alta en los procesos de recepción, compactación, fragmentación y acopio, debido al peso de la chatarra y de la maquinaria que se emplea en los procesos. Estas actividades han generado gran compactación en el área de influencia por lo que los enlaces de aglomerados se han fracturado, evitando que exista un correcto drenaje del agua a través del suelo.

- Calidad del suelo es la capacidad específica que tiene un suelo para funcionar en un ecosistema natural o antrópico (generado por el hombre). Calidad entonces es la capacidad de producir sin resultar degradado o sin perjudicar al ambiente. La salud de un suelo se determina por la evaluación a través del tiempo de su calidad (CONCET). 
La calidad del suelo se ve afectada principalmente en las etapas del proceso donde la chatarra se encuentra a la intemperie sobre el entorno natural pues hay incorporación de partículas ajenas a la constitución natural del suelo. Pequeñas cantidades de metales como, $\mathrm{Fe}, \mathrm{Cr}, \mathrm{Cu}, \mathrm{Mn}, \mathrm{Zn}$ y Ni, están presentes en concentraciones de partes por millón (SIGRAUTO). Estas pueden ser incorporadas al suelo por arrastre y lavado de materiales.

- En el componente ecosistémico se ven afectados los aspectos de flora y fauna con un impacto de importancia de +6 en todos las etapas de proceso debido a que su duración es permanente y su influencia es local en cuanto a su magnitud los valores difieren de acuerdo al espacio ocupado (área) y forma de transformación por las etapas de proceso, en ese sentido las etapas de proceso que ocupan más espacio y que han transformado más el medio desalojando especies (vegetales y animales) y haciendo que las mismas desaparezcan son las etapas de fragmentación, compactación y almacenamiento temporal y disposición del residuo de fragmentación, sin embargo, en general todas las etapas del proceso han cambiado e impactado con un grado de afectación medio a la fauna y flora. Finalmente es importante aclarar que el impacto no es altamente negativo debido a que el área donde se encuentran las sedes es de uso industrial por ende, se da por entendido que no existen especies animales y vegetales de significancia tal, que indiquen que su impacto sea relevante y requiera de un análisis e identificación especial de pérdida o desaparición de especies. 
- En cuanto a la implicación de estos impactos en el componente social, es importante mencionar que las actividades industriales que se realizan en las áreas de influencia (Tocancipá y Sogamoso) generan pasivos ambientales que no se pueden cuantificar debido a la falta de información de costos por ejemplo en recuperación de un metro cúbico de suelo (restaurar su textura).

- Otro aspecto a tener en cuenta es al interior de la empresa, las condiciones en las que labora el personal de las dos sedes contemplan mejoramiento de la calidad de vida, debido a que la empresa provee de garantías a la población en general al brindar oportunidades de trabajo, garantizar una remuneración justa de acuerdo a su experiencia o grado de desarrollo educativo, salud y oportunidades de crecimiento económico a nivel familiar, a su vez la empresa se preocupa por el bienestar físico y sicológico de sus trabajadores.

- Desde la dimensión económica el proceso de chatarrización genera mejoramiento en la calidad de vida de la población de la región. La chatarrización desde la concepción actual, generador de insumos para el proceso de siderurgia y este a su vez fabricación de aceros para el área de construcción, lleva inmerso el componente de bienestar para la región y del país.

- Otro aspecto de implicación social y que está directamente relacionado con el proceso de chatarrización es el mejoramiento de la calidad del aire en particular debido a la disminución de las cargas contaminantes aportadas por los vehículos en mal estado, debido a una vida útil extensa. 


\subsection{Propuesta de manejo}

Las alternativas de gestión presentadas a continuación están direccionadas al mejoramiento de la calidad del ambiente, por ejemplo disminución en la generación de residuos que colmatan rellenos sanitarios, emisiones de cargas contaminantes por procesos que no contemplan tecnologías de punta y otros que no se mencionan por lo extenso del tema.

Para el desarrollo del presente proyecto se realizó el análisis de diferentes tecnologías, a continuación se presentan las más viables de acuerdo con las características de los subproductos generados en el proceso de chatarrización. Teniendo en cuenta que los plásticos después de los metales son el producto con mayor representatividad en los vehículos fuera de uso, es importante revisar las ventajas que este material ofrece especialmente porque reduce el peso del vehículo lo que implica un menor consumo de combustible y por ende disminución de emisiones a la atmosfera.

Las alternativas de gestión para este subproducto son:

- Pirolisis. La pirolisis es un proceso termoquímico que ocurre en ausencia de oxígeno. El proceso de pirolisis tiene tres etapas: la dosificación y alimentación de la materia prima, la transformación de la masa orgánica y, finalmente, la obtención y separación de los productos (coque, aceite y gas) (PUCP, 2012). Gracias al gran poder calorífico que presentan los plásticos se tienen grandes contenidos energéticos en los subproductos, de tal manera los subproductos obtenidos son susceptibles a 
ser comercializados o reconvertidos en fuente de energía eléctrica, obteniéndose ingresos y un beneficio económico a costas de una forma de aprovechamiento energético.

- Gasificación. La gasificación es el conjunto de reacciones termoquímicas, que se producen en un ambiente pobre en oxígeno, y que da como resultado la transformación de un sólido, en este caso residuos plásticos, en una serie de gases susceptibles de ser utilizados en una caldera, turbina o en un motor, tras ser debidamente acondicionados. El agente gasificante es un gas, o una mezcla de gases, que aportan calor para iniciar las reacciones, y oxígeno .

En cuanto a los metales no ferrosos existen diferentes tipos de éstos en un vehículo fuera de uso. Los metales no ferrosos comprenden todos los metales a excepción del hierro y que carecen de la propiedad de magnetismo que es la principal diferencia entre lo metales ferrosos y no ferrosos. Su utilización no es tan masiva como los productos férreos (hierro, acero), pero tienen una gran importancia en la fabricación de vehículos, por el bajo peso específico, la resistencia a la oxidación, la fácil manipulación y mecanizado.

Las alternativas para el aprovechamiento, reciclaje y valorización de este subproducto van encaminadas principalmente a la separación de los metales no ferrosos del producto de fragmentación para su posterior venta y comercialización.

- Separación por medios densos - venta de metales no ferrosos: En este tipo de plantas se recibe la fracción Residuo Pesado -compuesta por gomas, plásticos y otros materiales metálicos, en su mayoría no férricos- que se genera en las plantas fragmentadores. Esta fracción es sometida a distintos procesos de segregación (separar los distintos metales férricos y no férricos útiles en fundición, 
aluminio, cobre, etc.), de otras fracciones de materiales no metálicos que se depositan en el vertedero, o bien se reciclan o se valorizan energéticamente.

- Separación por Corrientes de Foucault - venta de metales no ferrosos. Está basado en un campo magnético alternativo, es decir, en un campo magnético donde el polo Norte y el Sur cambian alternativamente. Si el metal no férrico está sometido a un campo magnético alternativo, se crearán unas corrientes internas denominadas Corrientes de Foucault. Dichas Corrientes de Foucault generan un campo magnético opuesto al campo magnético generado por el imán. Esta fuerte oposición de campos magnéticos provoca una repulsión entre ellos y, por tanto, el metal no férrico será literalmente despedido de su trayectoria natural separándose del resto de materiales.

Dentro de la familia del vidrio que se encuentra clasificada en vidrio de uso doméstico e industrial. El vidrio proveniente de los vehículos fuera de uso es de tipo industrial. Proviene de las lunas laminadas, utilizadas generalmente en la parte delantera, y de las ventanas laterales, generalmente de vidrio templado.

Las lunas laminadas suelen ser rechazadas por la industria que recicla el vidrio con este mismo fin, dado que están construidas por dos láminas de vidrio recocido, unidas por una finísima película de polivinil butiral, que es un polímero de alta elasticidad y flexibilidad y que se utiliza para dotar a la luna de las condiciones elásticas específicas para su homologación. Pero este polímero plantea un problema para el reciclado, ya que, al ser plástico, no se mezcla bien en el proceso de triturado y fusión del vidrio, constituyéndose como un contaminante de la mezcla. Por tanto sus posibilidades de aprovechamiento, reciclaje o reincorporación a una cadena de producción están limitadas. 
En ese sentido es conveniente analizar la posibilidad de enviar un residuo de esta categoría a rellenos sanitarios.

- Agregados a la Producción de Materiales de Construcción. Los vidrios industriales, pueden ser utilizados como agregados para la producción de materiales para construcción, tales como ladrillos y tejas de arcilla, bloques, etc., y árido ligero para el concreto.

- Agregado para la Producción de GlasphalT. Este tipo de vidrio también pueden ser reutilizados en la producción de Glasphalt, un tipo de asfalto que contiene un porcentaje de vidrio triturado como agregado.

Los neumáticos de automóvil están formados por diferentes materiales como el acero, las fibras textiles y los elastómeros.

Un $70 \%$ de la masa de los neumáticos está constituida por derivados de hidrocarburos. El contenido energético medio de un neumático de turismo equivale a 27 litros de petróleo (21 litros en materias primas y 6 en el proceso de fabricación). Este potencial energético nos da una pista acerca de las posibles técnicas de eliminación provechosa de neumáticos de desecho .

A estos NFU hay que sumarles la cantidad de composites que posee un carro hechos de caucho, los cuales no poseen fibras textiles, ni acero anexo a su composición lo que facilita aún más su aprovechamiento o reciclaje.

Actualmente las empresas dedicadas a la chatarrización no tienen una alternativa para la gestión de este subproducto por ende a continuación se muestran una serie de alternativas enfocadas en la gestión del subproducto, basadas en el documento valoración material y energética 
de neumáticos fuera de uso realizado por el Círculo de Innovación en Materiales, Tecnología Aeroespacial y Nanotecnología (CIMTAN):

- Recauchutado. El proceso de recauchutado consiste en sustituir las gomas viejas del neumático y reconstruir su estructura original convirtiéndolo en un neumático de características similares al nuevo.

- Tratamiento mecánico. Proceso mecánico mediante el cual los neumáticos son comprimidos, cortados o fragmentados en piezas irregulares. Entre ellos se encuentran fabricación de balas, troceado (ripping), trituración (cutting).

- Molienda o Tecnología de reducción de tamaño. Este proceso se puede realizar previo a la disposición en rellenos sanitarios y con esto se disminuye el volumen.

- Pirólisis - Termólisis. En el proceso de pirólisis se calientan los trozos de neumático $(1-3 \mathrm{~cm})$ a temperatura moderada $\left(400-800^{\circ} \mathrm{C}\right)$ en ausencia de oxígeno o con una cantidad limitada del mismo. La degradación térmica del material produce una descomposición del neumático donde los elementos orgánicos volatilizables (principalmente cadenas de caucho) se descomponen en gases y líquidos, y los elementos inorgánicos (principalmente acero y negro de carbono no volátil) permanecen como residuo sólido.

- Co-procesamiento. Hornos de cementeras o fábricas de pasta de papel. Los neumáticos atendiendo a un proceso anterior de triturado logrando dimensiones específicas (granos de aproximadamente $5 \times 5 \mathrm{~cm}$ ) pueden ser utilizados como combustible, debido a que su estructura está formada principalmente por carbono dándole de esta manera un gran poder calorífico de aproximadamente $34890 \mathrm{~kJ} / \mathrm{kg}$. 
Para este subproducto es importante realizar el análisis de los procesos y las tecnologías de punta aplicadas para determinar las cargas contaminantes emitidas, para que cumplan con la normativa de calidad del aire nacional.

Los residuos peligrosos tienen dos alternativas, la primera es llevar su gestión siguiendo los lineamientos proporcionados por la legislación colombiana en cuanto a residuos peligrosos se refiere, la segunda está encaminada al manejo especial por su característica de peligrosidad, pero los residuos no están exentos de ser aprovechados, reciclados o reintroducidos a una cadena productiva.

Es importante resaltar que la gestión que deben llevar las entidades dedicadas a la chatarrización vehicular, en cuanto a residuos peligrosos, es recomendable que este tipo de industrias cuenten con su propio relleno de seguridad, con las medidas de manejo, seguimiento y monitoreo de acuerdo a la normativa nacional.

Todas las alternativas planteadas anteriormente proporcionan beneficios técnicos, tecnológicos, ambientales, financieros, económicos y sociales. 


\section{Conclusiones}

- El proceso de chatarrización vehicular impacta negativa y fuertemente el componente geosférico, principalmente en aspectos ambientales como: la calidad del suelo, erosión y textura. Es posible afirmar que este componente es el más afectado porque las etapas de proceso que maneja la entidad chatarrizadora ocurren a la intemperie, sin ningún tipo de cobertura superior o inferior que garantice que no se está trabajando sobre el entorno natural.

- El componente impactado positivamente por las actividades de chatarrización es el socioeconómico, dado que las entidades encargadas son una fuente generadora de empleo. Por ejemplo, Sidenal cuenta con un cuerpo laboral de más de 700 personas. Igualmente, la posibilidad de ofrecer empleo exige que las empresas brinden seguridad, afiliación a la salud para los trabajadores y sus familias, y oportunidades para el mejoramiento de vida social y moral de los empleados.

- A través de un proceso de desmontaje de un vehículo tipo taxi (con peso de $870 \mathrm{~kg}$ ), se identificaron los residuos producidos y su representatividad. Se encontró que los metales ferrosos corresponden al $67,7 \%$ del vehículo; los plásticos, al 9,66\%; los residuos peligrosos, al 7,15\%; los metales no ferrosos, al $6,46 \%$; el caucho y los neumáticos fuera de uso, al 4,45\%; el vidrio, al 3,74 \%; y finalmente, los denominados "Otros" (espuma, plástico, aluminio, textil, cartón, entre otros) equivalen al 0,75\%.

- Para el manejo del subproducto plástico se identificaron ocho alternativas. Según el estudio de ponderación, solo de ellas son las más viables en las entidades 
chatarrizadoras. La primera se denomina pirólisis, una tecnología de tratamiento termoquímico que ofrece la gestión de los residuos plásticos, así como la del caucho y los NFU, y el residuo de fragmentación en general. La segunda alternativa se denomina entrega a empresas recuperadoras, que ofrece la posibilidad de entregarlo o vender el residuo a un tercero, para que este lo aproveche.

- Para el manejo del subproducto caucho -NFU, se identificaron ocho alternativas, de las cuales aparte de las escogidas para los plásticos, se seleccionaron dos alternativas más: la molienda o tecnología de reducción de tamaño, escogida principalmente por su alta aplicabilidad en el mercado; la segunda es el co-procesamiento, el cual se aprovecha el gran poder calorífico que tiene el caucho para ser combustible de entrada, por ejemplo, en la producción de cemento.

- Para el manejo de los metales no ferrosos se seleccionaron alternativas basadas principalmente en la identificación y la separación de los componentes del resto de residuos. Se escogieron dos procedimientos: la separación por medios densos y la separación por corrientes de Foucault. Se concluyó que cualquiera de las alternativas, sin importar su viabilidad, apunta a la comercialización y venta del metal no ferroso para posterior fundición.

- Las alternativas para la gestión del vidrio tienen una fuerte limitación porque el vidrio de los vehículos está compuesto por dos láminas de vidrio recocido, unidas por una finísima película de polímero de alta elasticidad y flexibilidad, lo que hace que la industria rechace la idea de reciclar o aprovechar el vidrio. Sin embargo, se identificaron dos alternativas enfocadas en el uso del vidrio como un agregado para la producción de materiales de construcción y asfalto. Sería preciso analizar 
la viabilidad de la disposición del vidrio en un vertedero controlado.

- Los residuos peligrosos pueden seguir un manejo con base en la política de gestión de residuos peligrosos, en especial, el Decreto 4741 de 2005. No obstante, se proponen alternativas por tipo de residuo peligroso, muchas de ellas de fácil aplicabilidad y gran probabilidad de obtener un beneficio económico y ambiental. Tal es el caso de los aceites usados, los cuales pueden ser reutilizados, reprocesados o aprovechados energéticamente, tanto en las instalaciones de la entidad chatarrizadora, como para su venta y comercialización a terceros.

\section{Recomendaciones y trabajo posterior}

- Las empresas dedicadas a la chatarrización vehicular deben, sin duda, implementar entre sus procesos una etapa de desmontaje de los componentes. De esa manera, se asegura una correcta identificación y clasificación de los materiales aprovechables. En el caso de que no se incluyan etapas como la de desmontaje, las entidades chatarrizadoras deben dirigir sus esfuerzos hacia las alternativas de manejo de residuos en el residuo de fragmentación. 
- Es importante que todas las etapas de proceso estén debidamente señalizadas y que cumplan los reglamentos de seguridad industrial y salud ocupacional, para evitar accidentes laborales. El seguimiento de esas directrices de parte de la entidad garantiza una mejora sustentable ambientalmente y una mitigación notable de impactos ambientales.

- Se recomienda la creación de una normatividad que rija específica y detalladamente el proceso de chatarrización, tanto en el ámbito distrital como en el nacional. Dentro de esa normatividad se debe incentivar la creación de directrices para el proceso de chatarrización, guías (técnicas, ambientales) que fortalezcan el manejo de este sector. De esa manera, se garantiza un mejor futuro para el sector de la movilidad y el papel que desempeña la chatarrización vehicular en esa área.

- Se recomienda implementar un plan de manejo integral de los residuos provenientes del proceso de chatarrización de vehículos, para identificar los actores involucrados, así como crear normas internas que regulen las etapas de proceso, todo con propósitos de eficiencia y eficacia. Con la implementación de esas medidas, se logra que los materiales que entran sean $100 \%$ utilizables y que Colombia esté a la vanguardia de grandes países como Japón y como los de la Unión Europea, en cuanto al manejo de los VFU.

- Se recomienda realizar procesos de desmontaje y caracterización de los residuos peligrosos provenientes de otro tipo de vehículos como buses, busetas y microbuses, para ampliar la información de la producción de residuos en los vehículos de servicio público, debido a que estos vehículos presentan diferentes pesos y la representatividad de sus componentes puede variar. 


\section{Referencias bibliográficas}

Acoplásticos (2011-2012). Directorio colombiano de reciclaje de residuos plásticos. Colombia, Bogotá, D. C.

Aguado, J., Serrano, D. P., Escola, J. M. \& Briones, L. (2011). El papel de la química en la valorización de los residuos plásticos. An. Química, 107(1), pág. 76-83.

Cano S. E., Cerezo G.L. \& Urbina F. M. (2007). Valorización material y energética de neumáticos fuera de uso. España.

Cámara de Comercio de Bogotá \& Ministerio de Medio Ambiente. (2006). Guía para el manejo de llantas usadas. Colombia. Bogotá, D.C: Editorial Kimpres Ltda.

Centro de actividades regionales para la producción limpia (CAR/PL). (2001). Posibilidades de reciclaje y aprovechamiento de los aceites usados. Barcelona, España.

Jeff, S., \& Gregory A. K. (2001). Management Of End-Of Life Vehicles (Elvs) In The US. Michigan: University of Michigan.

Ministerio de ambiente, vivienda y desarrollo territorial. (2005). Política Ambiental para la Gestión Integral de Residuos o Desechos Peligrosos. Colombia. Bogotá, D. C. 
Ministerio de ambiente, vivienda y desarrollo territorial (2008). Construcción de Criterios Técnicos para el Aprovechamiento y Valorización de Residuos Sólidos Orgánicos con Alta Tasa de Biodegradación, Plásticos, Vidrio, Papel y Cartón. Colombia, Bogotá, D. C.

Ministerio de Ciencia y Tecnología de ESPAÑA. (2001). Valorización energética de residuos generados durante y al final de la vida de los vehículos. España.

Muñoz, C., Moliner, E., Garraín, D., Franco, V. \& VidaL, R. (2012). Alternativas para la gestión del residuo de fragmentación del automóvil. Departamento de Mecánica y Producción Industrial, Escuela Politécnica Superior de Mondragón (EPS). Pág. 12.

Muñoz, M. C., Vidal. R. \& Justel L. D. (2010). Análisis ambiental del proceso de fin de vida de vehículos en España. España.

Shin-Ichi, S., Hideto, Y., Hiratsuka, J., Vandecasteele, C., Kohlmeyer, R. \& Yano, J. (2014). An International Comparative Study Of End-Of-Life Vehicle (ELV) recycling systems. J Mater Cycles Waste Manag 16, pág. $1-20$.

Secretaria de Movilidad. (2012). Movilidad en Cifras 2012. Colombia, Bogotá, D.C 